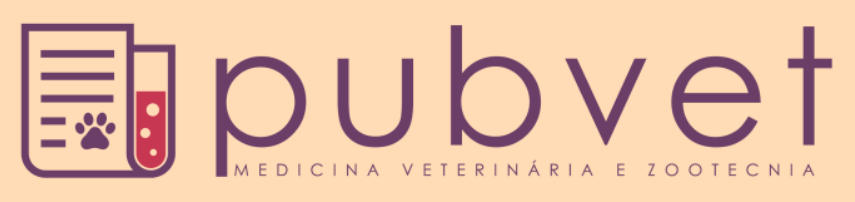

ISSN $1982-1263$

https://doi.org/10.22256/pubvet.v12n5a84.1-6

\title{
Perfil de resistência de Staphylococcus aureus isolados de pescada amarela (Cynoscion acoupa) comercializada em feira pública
}

\author{
Anderson Luís Pena da Costa ${ }^{\ominus 1}$, Jaqueline Freitas do Nascimento ${ }^{\ominus 2}$, Antonio Carlos \\ Souza da Silva Júnior $3^{*}$
}

\footnotetext{
${ }^{1}$ Acadêmico de Farmácia, Instituto Macapaense do Melhor Ensino Superior. Macapá-AP Brasil. E-mail: pena.pharmacist91@ gmail.com

${ }^{2}$ Acadêmica de Farmácia, Instituto Macapaense do Melhor Ensino Superior. Macapá-AP Brasil. E-mail: jackllinefn@hotmail.com

${ }^{3}$ Pesquisador do Instituto de Pesquisas Científicas e Tecnológicas do Estado do Amapá, Núcleo de Ciência e Tecnologia de Alimentos. Macapá-AP Brasil. E-mail: jr_bio2005@yahoo.com.br

*Autor para correspondência
}

\begin{abstract}
RESUMO. A feira do produtor rural da cidade de Macapá exerce um importante papel econômico, social e cultural para os habitantes locais e da região comercializando recursos que são produto de seu agroextrativismo, pecuária e pesca. A pescada amarela (Cynoscion acoupa), é um peixe nativo da região e é um produto muito importante para o negócio local. Uma análise microbiológica foi conduzida sobre amostras de pescada amarela coletadas na feira do produtor rural da cidade de Macapá, onde o objetivo deste trabalho foi determinar a incidência e perfil de resistência da bactéria Staphylococcus aureus. Dos 20 peixes analisados, 15 foram positivos (75\%), com uma concentração média de $4 \times 10^{4}$ UFC's ( \pm $\left.1 \times 10^{5}\right)$, dos quais 8 peixes (40\%) estavam fora do padrão tolerável pela agência nacional reguladora. Quanto ao perfil de resistência, as cepas analisadas foram suscetíveis aos antibióticos ceftriaxona (13,33\%), oxacilina (100\%), clindamicina $(13,33)$, cotrimoxazol $(100 \%)$ e vancomicina (13,33\%); intermediárias aos antibióticos ceftrioxona (93,33\%), clindamicina $(13,33 \%)$ e eritromicina $(66,67 \%)$; e resistentes aos antibióticos penicilina $(100 \%)$, clindamicina $(66,67 \%)$, vancomicina $(86,67 \%)$ e eritromicina $(33,33 \%)$. Indicando este estudo que o peixe analisado pode ser uma fonte de $S$. aureus com diferentes perfis de resistência a antibióticos e uma preocupação para a saúde pública.
\end{abstract}

Palavras chave: contaminação, higiene, pescado, qualidade

\section{Resistance profile of Staphylococcus aureus strains isolated from Acoupa weakfish (Cynoscion acoupa) commercialized in public fair}

\begin{abstract}
The rural producer market of Macapa city (AP) plays an important economic, social and cultural role by commercializing resources that are the result of their agroextractivism, farming, and fishing. The Acoupa Weakfish (Cynoscion acoupa), is native to this region and a very important product for local businesses. A microbiological analysis was conducted over samples of the Acoupa Weakfish collected from the rural producer market of Macapa city, where the goal of this work was to determine the incidence and antibiotic resistance profile of the bacteria Staphylococcus aureus. Out of the 20 fish sampled, bacteria were detected in 15 fish ( $75 \%$ of the sample) with a mean concentration of $4 \times 10^{4}$ CFUs $\left( \pm 1 \times 10^{5}\right)$; of the 15 fish identified with the bacteria, only 7 fish $(35 \%)$ specifically contained Staphylococcus sp at $1 \times 10^{3} \mathrm{CFU}$ concentration, which is considered tolerable by the national regulatory agency. According to the assay performed to evaluate the antibiotic resistance profile, the strains analyzed were susceptible to ceftriaxone $(13.33 \%)$, oxacillin $(100 \%)$, clindamycin $(13.33 \%)$, cotrimoxazole $(100 \%)$ and vancomycin (13.33\%); intermediate to ceftriaxone $(93.33 \%)$, clindamycin $(13.33 \%)$ and
\end{abstract}


erythromycin (66.67\%); and resistant to penicillin (100\%), clindamycin $(66.67 \%)$ and vancomycin (86.67\%) and erythromycin $(33,33 \%)$. The findings of this study indicate that the analyzed fish can be a source of Staphylococcus sp with different antibiotic resistance profiles, and a public health concern.

Keywords: contamination, fish, hygiene, quality

\title{
Perfil de resistencia de Staphylococcus aureus aislados de Cynoscion acoupa comercializada en feria pública
}

\begin{abstract}
RESUMEN. La feria del productor rural de la ciudad de Macapá ejerce un importante papel económico, social y cultural para los habitantes locales y de la región comercializando recursos que son producto de su agroextractivismo, pecuaria y pesca. La Cynoscion acoupa, es un pescado nativo de la región y es un producto muy importante para el negocio local. Un análisis microbiológico se llevó a cabo sobre muestras de merluza amarilla recogidas en la feria del productor rural de la ciudad de Macapá, donde el objetivo de este trabajo fue determinar la incidencia y perfil de resistencia de la bacteria Staphylococcus aureus. De los 20 anaimales analizados, 15 fueron positivos (75\%), con una concentración media de $4 \times 10^{4}$ UFC's $\left( \pm 1 \times 10^{5}\right)$, de los cuales 8 peces $(40 \%)$ estaban fuera del estándar tolerable por la agencia nacional reguladora. En cuanto al perfil de resistencia, las cepas analizadas fueron susceptibles a los antibióticos ceftriaxona (13,33\%), oxacilina (100\%), clindamicina $(13,33)$, cotrimoxazol $(100 \%)$ y vancomicina $(13,33 \%)$; intermediarios a los antibióticos ceftrioxona (93,33\%), clindamicina (13,33\%) y eritromicina $(66,67 \%)$; y resistentes a los antibióticos penicilina (100\%), clindamicina $(66,67 \%)$, vancomicina $(86,67 \%)$ y eritromicina $(33,33 \%)$. Indicando con este estudio que el pescado analizado puede ser una fuente de $S$. aureus con diferentes perfiles de resistencia a antibióticos y un motivo de preocupación para la salud pública.
\end{abstract}

Palabras clave: calidad, contaminación, higiene, pescado

\section{Introdução}

A cultura de comercialização de produtos alimentícios em feiras livres foi introduzida no Brasil como uma herança portuguesa, onde é considerado o modelo de mercado periódico mais antigo e tradicional do país (Medeiros-Júnior et al., 2015). Por outro lado, apresentam problemas sérios sanitários em diversas etapas, além da conservação dos produtos, o que pode refletir diretamente na saúde do consumidor, diminuindo a procura pelo produto, além de poluição ambiental (Silva Junior et al., 2016).

Em Macapá, Feira do Produtor Rural unidade Buritizal está localizada na Avenida Claudomiro de Moraes, s/n, bairro Buritizal, Macapá-Amapá. Funciona semanalmente todas as terças e quintasfeiras, das $14 \mathrm{hs}$ às $21 \mathrm{hs}$, com venda direta de produtos variados e capacidade de atendimento de 316 boxes. Atende anualmente 3.291 feirantes produtores, distribuídos nas 292 comunidades do Estado, que participam através de escala prédeterminadas pela Secretaria de Desenvolvimento Rural (Silva Júnior et al., 2017). As feiras em Macapá não são apenas parte de um projeto político, específico para a cidade, mas também um fator que contribui significativamente na diversidade sócio espacial local por atuarem 1) como uma alternativa de abastecimento para cidade: produtos agrícolas provenientes do campo (feira do produtor rural), produtos provenientes dos rios, ilhas e cidades ribeirinhas (feiras das margens de igarapés) e produtos vindos de outras regiões (comércio de rua); 2) acompanharem, mesmo que de forma marginal a estruturação e expansão da cidade; e 3) contribuíram para o estabelecimento da produção de uma rede de relações, via circuito inferior, da cidade de Macapá tanto com diferentes cidades do nordeste brasileiro, em função do abastecimento, quanto com as cidades da Ilha do Marajó e do baixo Amazonas (Amaral, 2016). Amaral (2016), também considera que as feiras são importantes para a população não só por abastecerem a cidade com produtos alimentícios, mas também por ajudarem a construir uma alternativa de sobrevivência, fora da lógica do mercado formal, para um grande número de pessoas, cujos destinos passam a ser auto definidos (autônomos), sem a mediação de uma empresa, sem aquele processo 
tradicional capitalista de subordinação formal ao mercado.

Neste contexto, a feira do Agricultor Rural é uma feira muito movimentada, que abastece o bairro do buritizal, os bairros arredores e é frequentada por muitos consumidores de outros logradouros mais afastados, devendo por tanto os produtos nela comercializados atenderem a padrões mínimos que garantam ao consumidor segurança alimentar e nutricional, nas quais, práticas que preservem a qualidade dos alimentos, as condições ambientais para a produção, o desenvolvimento sustentável e a qualidade de vida da população em geral devem ser empregados para assegurar condições de acesso a alimentos básicos, seguros e de qualidade, em quantidade suficiente e de modo permanente, sem comprometer o acesso da população a outras necessidades essenciais (Freitas \& Pena, 2007).

Sendo o objetivo deste trabalho investigar a incidência de bactérias do gênero Staphylococcus aureus em amostras de pescada amarela (Cynoscion acoupa) comercializada na feira do produtor rural do bairro do buritizal, e avaliar o perfil de resistência dos isolados obtidos a diferentes antibióticos, visto que a resistência aos antibióticos representa um problema de saúde pública.

\section{Material e Métodos}

Foram adquiridas 20 amostras de Pescada amarela na feira do Produtor Rural, unidade Buritizal, na cidade de Macapá, embaladas pelos próprios comerciantes e transportadas em caixas isotérmicas até o laboratório de microbiologia do Instituto de Pesquisas Científicas e Tecnológicas do Estado do Amapá - IEPA. O tempo entre a coleta e a análise não ultrapassou 60 minutos.

\section{Preparo do Homogenato de Peixe, Cultivo e Critérios para o Isolamento}

Foi utilizado $20 \mathrm{~g}$ da amostra em $180 \mathrm{ml}$ de Salina Peptonada 0,1\% (H2Op) seguindo a recomendação da ISO 6887-1 (1999), e posterior diluição seriada no mesmo diluente até a diluição 10-3. A partir desta, foi inoculado $0,1 \mathrm{ml}$ distribuído na superfície de placas de Ágar BairdParker (BP) e foram incubadas, investidas, a 35$37^{\circ} \mathrm{C} / 45$ - 48h. Após o período de incubação foi realizada contagem padrão de colônias típicas de Staphylococcus, possuindo as características: circulares, pretas ou cinza escuras, com 2-3mm de diâmetro, lisas, convexas, com bordas perfeitas, massa de células esbranquiçadas nas bordas, rodeadas por uma zona opaca e/ou um halo transparente que se estende para além da zona opaca.

\section{Identificação bioquímica}

Com intuito de confirmação foi realizada a coloração de Gram e identificação bioquímica, catalase, coagulase e DNase (Brasil, 2003). Ainda foram realizadas as provas de utilização de glicose e maltose, utilização de manitol e crescimento em $\mathrm{NaCl}$ a 7,5\% com o intuito de diferenciar S. aureus de outros $S$. Coagulase-Positivos.

\section{Caracterização do Perfil de Resistência}

O perfil de resistência dos $S$. aureus isolados foi avaliado seguindo a técnica de disco difusão (CLSI 2015) onde foram utilizados os discos comerciais dos seguintes antibióticos: ceftriaxona $30 \mu \mathrm{g}$ (CRO), clindamicina $2 \mu \mathrm{g}$ (CLI), cotrimoxazol $25 \mu \mathrm{g}$ (SUT), eritromicina $15 \mu \mathrm{g}$ (ERI), oxacilina $1 \mu \mathrm{g}$ (OXA), penicilina G $10 \mathrm{UI}$ (PEN), e vancomicina $30 \mu \mathrm{g}$ (VAN). Sendo o perfil de resistência categorizado em sensível (se o tamanho dos halos for $>23 \mathrm{~mm}$ para eritromicina, $>29 \mathrm{~mm}$ para penicilina, $>15 \mathrm{~mm}$ para vancomicina, $>13 \mathrm{~mm}$ para oxacilina, $>21$ $\mathrm{mm}$ para ceftriaxona, $>21 \mathrm{~mm}$ para clindamicina e > $21 \mathrm{~mm}$ para cotrimoxazol), intermediario (se o tamanho dos halos for igual a $14-22 \mathrm{~mm}$ para eritromicina, $11-12 \mathrm{~mm}$ para oxacilina, $14-20 \mathrm{~mm}$ para ceftriaxona, $15-20 \mathrm{~mm}$ para clindamicina e 15-20 mm para cotrimoxazol, não havendo essa categoria de perfil para a vancomicina e penicilina) e resistente (se o tamanho dos halos for $<13 \mathrm{~mm}$ para eritromicina, < $28 \mathrm{~mm}$ para penicilina, $<15 \mathrm{~mm}$ para vancomicina, $<10 \mathrm{~mm}$ para oxacilina, $<13 \mathrm{~mm}$ para ceftriaxona, $<14$ $\mathrm{mm}$ para clindamicina $\mathrm{e}<10 \mathrm{~mm}$ para cotrimoxazol).

\section{Resultados e Discussão}

Da amostragem de pescado analisada, constituída por 20 peixes foi detectado pela metodologia empregada neste trabalho a presença Staphylococcus aureus em 15 peixes $(75 \%$ da amostragem) na concentração média de $4 \times 10^{4}$ $\mathrm{UFC} / \mathrm{g}\left( \pm 1 \times 10^{5}\right)$, das quais apenas 7 peixes $(35 \%)$ continham $S$. aureus na concentração de $1 \times 10^{3}$ $\mathrm{UFC/g}$, considerada tolerável pela RDC número 12 de 02 de Janeiro de 2001 da ANVISA (Brasil, 2001) que determina os parâmetros técnicos e de segurança microbiológicos aplicados aos alimentos no Brasil. 
Em um trabalho similar realizado no mercado local de peixe da cidade de Guntur na Índia, Bujjamma \& Padmavathi (2015) apontam como fontes de contaminação dos pescados comercializados com a bactéria Staphylococcus aureus a manipulação inadequada pelos feirantes e consumidores. A conservação imprópria do alimento com o uso de gelo (água) contaminado, condições de armazenamento que favorecem a contaminação cruzada do pescado com outros alimentos que apresentam uma microbiota intrínseca distinta da encontrada na carne do peixe e a contaminação terciária mediada por moscas são fatores que promovem inoculação e a contaminação dos produtos seguida de deterioração do alimento e potencial aumento dos casos de infecto intoxicação alimentar entre os consumidores de pescado. Silva Júnior et al. (2015) avaliando a Pescada Branca (Cynoscion sp.) comercializados na feira do Perpétuo Socorro, Macapá-AP encontraram em 50\% das amostras a presença de Staphylococcus Coagulase Positiva. Em relação a contaminação do pescado pela bactéria $S$. aureus, é importante ressaltar que esta é frequentemente encontrada na pele e nas mucosas humanas (Sales \& Silva, 2012) havendo estimativas de que $20-30 \%$ da população mundial em geral seja portadora deste patógeno facultativo (Plata et al., 2009) com alta incidência em pescados comercializados no Brasil (Novotny et al., 2004).

A contaminação do pescado por Staphylococcus spp pode ainda ser atribuída a fatores ambientais como a contaminação dos hábitats aquáticos por esgoto e a microbiota permanente e transitória dos peixes, na qual o Staphylococcus spp pode ser tanto um comensal ou um contaminante ambiental. Porém é muito difícil fazer essa distinção em relação a origem da bactéria, mas já foi demonstrado que em Cuprinus carpio e em Sirlus glanis que esta bactéria é comum na pele, fígado, intestinos e músculos, sendo, entretanto, a alta prevalência de Staphylococcus spp indicativo de práticas não higiênicas não só no ambiente, mas também na pós-pesca, comercialização e manipulação do pescado (Ali, 2014). Outro trabalho que demonstra que a quantidade de Staphylococcus aureus presente em ambientes aquáticos é a pesquisa de Abdel-Gawad et al. (2015) que demonstra que a incidência da bactéria é muito maior em Oreochromis niloticus (Tilápia do Nilo) quando estas são provenientes de corpos de água eutrofizados, do que em corpos de água com suas características biológicas, físico-químicas e bioquímicas mais preservados. Nos testes para a avaliação do perfil de resistência das cepas para os antibióticos eritromicina, oxacilina, ceftriaxona, clindamicina cotrimoxazol, vancomicina e penicilina, os resultados foram variados dentre as 15 cepas de Staphylococcus aureus isoladas, das quais:

1. O perfil sensível foi detectado para os antibióticos vancomicina $(13,3 \% ; \mathrm{n}=2)$, oxacilina $(100 \% ; \mathrm{n}=15)$, ceftriaxona $(13,3 \% ; n=2)$, clindamicina $(13,3 \%, n=2)$ e cotrimoxazol $(100 \% ; n=15)$, não sendo encontrados cepas sensíveis aos antibióticos eritromicina e penicilina;

2. O perfil intermediário foi encontrado nos testes com os antibióticos eritromicina $(66,7 \%, \mathrm{n}=10)$, ceftrioxona $(93,3 \% ; \mathrm{n}=$ 14) e clindamicina $(13,3 \% ; n=2)$, não sendo detectado o perfil de sensibilidade intermediário na amostragem analisada aos antibióticos vancomicina, oxacilina, penicilina e cotrimoxazol;

3. O perfil resistente foi observado nos testes com os antibióticos eritromicina $(33,3 \%$; $\mathrm{n}$ $=5)$, vancomicina $(86,7 \% ; \mathrm{n}=13)$, penicilina $(100 \% ; \mathrm{n}=15)$ e clindamicina $(66,7 \% ; n=10)$, não sendo detectado o perfil de sensibilidade resistente para os antibióticos oxacilina, ceftriaxona e cotrimoxazol.

A contaminação dos corpos de água pela atividade agrícola, industrial e doméstica é um dos fatores que tornam as águas inviáveis para o uso primário e secundário devido ao aumento do número de patógenos viáveis que se desenvolvem em águas contaminadas, infectando os organismos que lá vivem (Abdel-Gawad et al., 2015), também expondo a microbiota destes ambientes a compostos antimicrobianos que exercerão pressão seletiva no meio ambiente e selecionarão cepas resistentes a antimicrobianos, que por sua vez podem compartilhar genes de resistência entre diferentes comunidades microbianas, sejam elas patogênicas ou não, podendo originar sérios surtos de infecções resistentes em seres humanos (Costa \& Silva Junior, 2017).

A resistência aos antimicrobianos é resultado da adaptação dos microrganismos a pressão seletiva exercida por substâncias antagônicas de origem natural ou sintética presentes em seu meio, podendo esta ser: a) uma característica intrínseca de certas espécies de bactérias que podem resistir 
à ação de um dado antibiótico como resultado de um fator estrutural ou funcional inerente de dada espécie (Blair et al., 2015) ser adquirida como resultado de mutações que podem ocorrer durante a replicação celular ou serem induzidas por intermédio de agentes mutagênicos como radiações ionizantes e não ionizantes, agentes alquilantes ou espécies reativas de oxigênio (ROS) (Baptista, 2013); ou ainda c, adquirida pela aquisição de material genético exógeno anteriormente presente em outros microrganismos que contenham genes de resistência que são propagados por meio de mecanismos de transferência gênica horizontal (Baptista, 2013, Tavares, 2000) como a conjugação bacteriana, a transformação e a transdução (Džidić et al., 2008)

A análise realizada neste estudo indica que a pescada amarela (Cynoscion acoupa) obtida na feira do Produtor Rural, unidade Buritizal, na cidade de Macapá, pode ser considerada uma fonte de Staphylococcus aureus resistente a antibióticos devido a higiene inadequada e insatisfatória realização de boas práticas na cadeia mercadológica do pescado, hipostenizando-se que a resistência aos antibióticos observada possa ser proveniente da contaminação do habitat natural da Cynoscion acoupa por fármacos ou substâncias antimicrobianas, contaminação do pescado por meio de manipulador portador de Staphylococcus sp resistentes aos antibióticos testados, propondo- se ainda que a resistência detectada possa ainda ser fruto de transferência horizontal de genes entre populações bacterianas no ambiente natural.

Sendo necessários mais estudos para confirmar a origem da contaminação e dos fatores promotores da resistência bacteriana aos fármacos testados para melhor compreender os fatores que contaminam o pescado e intervir de forma eficaz, aumentando a segurança alimentar e contribuindo para a diminuição de casos de infecções e intoxicações alimentares.

Como medidas de prevenção e melhor manejo da cadeia logística do pescado e dos produtos comercializados em feiras é recomendado a contratação de um profissional responsável técnico com formação específica em alimentos (segurança alimentar) para a adequação dos estabelecimentos as boas práticas (Valente \& Passos, 2004), mas considerando que no caso das feiras a contratação de tal profissional pelos feirantes é inviável, funcionários públicos com a capacitação necessária poderiam assessorar os feirantes e propagar entre eles a realização das boas práticas. Outra medida que poderia ser adotada para prevenir a contaminação dos alimentos comercializados em feiras, seria a promoção de programas educativos que são de fácil implementação, baixo custo e podem ser muito eficazes a curto e longo prazo.

Tabela 1. Frequência e tamanho médio dos halos das cepas de Staphylococcus aureus isoladas a partir de amostras de pescada amarela (Cynoscion acoupa) comercializadas na Feira do Produtor Rural, Macapá-AP

\begin{tabular}{lcccccccccc}
\hline & \multicolumn{1}{c}{ Perfil de sensibilidade } \\
\cline { 2 - 10 } Antibiótico & \multicolumn{9}{c}{ Sensível } & \multicolumn{3}{c}{ Intermediário } & \multicolumn{2}{c}{ Resistente } \\
\cline { 2 - 10 } & $\mathrm{N}^{\circ}$ Cepas & $\%$ & $\begin{array}{c}\text { Média Halo } \\
(\mathrm{mm})\end{array}$ & $\mathrm{N}^{\circ}$ Cepas & $\%$ & $\begin{array}{c}\text { Média Halo } \\
(\mathrm{mm})\end{array}$ & $\mathrm{N}^{\circ}$ Cepas & $\begin{array}{c}\text { Média Halo } \\
(\mathrm{mm})\end{array}$ \\
\hline Ceftriaxona & 2 & 13,33 & $21( \pm 0,00)$ & 14 & 93,33 & $19,50( \pm 0,63)$ & 0 & 0 & 0 \\
Oxacilina & 15 & 100 & $15,73( \pm 1,58)$ & 0 & 0 & 0 & 0 & 0 & 0 \\
Penicilina & 0 & 0 & 0 & 0 & 0 & 0 & 15 & 100 & $21( \pm 1,75)$ \\
Clindamicina & 2 & 13,33 & $22,50( \pm 0,50)$ & 2 & 13,33 & $19,50( \pm 0,50)$ & 10 & 66,67 & $21,30( \pm 3,58)$ \\
Eritromicina & 0 & 0 & 0 & 10 & 66,67 & $21,70( \pm 0,46)$ & 5 & 33,33 & $23( \pm 0)$ \\
Cortrimoxazol & 15 & 100 & $22,67( \pm 1,07)$ & 0 & 0 & 0 & 0 & 0 & 0 \\
Vancomicina & 2 & 13,33 & $15( \pm 0,00)$ & 0 & 0 & 0 & 13 & 86,67 & $13,38( \pm 0,62)$ \\
\hline
\end{tabular}

\section{Referências Bibliográficas}

Abdel-Gawad, F. K., Eweda, W. E., El-Taweel, G. E., Shehata, S. F. \& Tawab, M. I. A. 2015. Detection of Staphylococcus aureus from fish and water samples collected from Lake Qarun. Environments, 6, 366-372.

Agencia Nacional de Vigilância Sanitária (Brasil). Resolução da Diretoria Colegiada nº 12 , de 2 de janeiro de 2001. Regulamento Técnico sobre Padrões Microbiológicos para Alimentos. Diário Oficial da União 20 dez 2000; Seção 1.

Ali, H. H. 2014. Isolation and identification of Staphylococcus bacteria from fish of fresh water and its antibiotics sensitivity in mosul city. Basrah Journal of Veterinary Research, 1, 33-42. 
Amaral, M. D. B. 2016. As feiras em cidades médias da Amazônia: as relações desenhadas a partir das experiências nas cidades de MarabáPA, Macapá-AP e Castanhal-PA. GEOUSP: Espaço e Tempo, 20, 376-391.

Baptista, M. G. F. M. 2013. Mecanismos de Resistência aos Antibióticos. Ciências Farmacêuticas. Universidade Lusófona de Humanidades e Tecnologia.

Blair, J. M. A., Webber, M. A., Baylay, A. J., Ogbolu, D. O. \& Piddock, L. J. V. 2015. Molecular mechanisms of antibiotic resistance. Nature Reviews Microbiology, 13, 42-51.

Bujjamma, P. \& Padmavathi, P. 2015. Prevalence of Staphylococcus aureus in fish samples of local domestic fish market. International Journal of Current Microbiology and Applied Sciences, 4, 427-433.

Clinical and Laboratory Standards Institute. 2015. Performance Standards for Antimicrobial Disk Susceptibility Tests: Approved Standard. M02A12. $12^{\mathrm{a}}$ ed. Wayne: Clinical and Laboratory Standards Institute.

Costa, A. L. P. \& Silva Junior, A. C. S. 2017. Resistência bacteriana aos antibióticos e saúde pública: uma breve revisão de literatura. Estação Científica (UNIFAP), 7, 45-57.

Džidić, S., Šušković, J. \& Kos, B. 2008. Antibiotic resistance mechanisms in bacteria: biochemical and genetic aspects. Food Technology \& Biotechnology, 46, 11-21.

Freitas, M. C. S. \& Pena, P. G. L. 2007. Segurança alimentar e nutricional: a produção do conhecimento com ênfase nos aspectos da cultura. Revista de Nutrição, 20, 69-81.

ISO 6887-1. 1999. Microbiology of food and animal feeding stuffs - Preparation of test samples, initial suspension and decimal dilution for microbiological examination - Part 1: General rules for the preparation of the initial suspension and decimal dilutions, $1^{\mathrm{a}} \mathrm{ed}$. The International Organization for Standardization.

Medeiros-Júnior, E. F., Eiras, B. J. F., Rodrigues, E. C. \& Alves, M. M. 2015. Avaliação higiênico-sanitária do pescado comercializado na cidade de Bragança Pará. Nutritime Revista Eletrônica, 12, 4237-4243.

Ministério da Agricultura, Pecuária e Abastecimento (Brasil). Instrução Normativa 62, de 26 de agosto de 2003. Métodos analíticos oficiais para análises microbiológicas para controle de produtos de origem animal e água. Diário Oficial da União 18 de Set 2003; Seção 1.

Novotny, L., Dvorska, L., Lorencova, A., Beran, V. \& Pavlik, I. 2004. Fish: a potential source of bacterial pathogens for human beings. A review. Veterinarni Medicina, 49, 343-358.

Plata, K., Rosato, A. E. \& Wegrzyn, G. 2009. Staphylococcus aureus as an infectious agent: overview of biochemistry and molecular genetics of its pathogenicity. Acta Biochimica Polonica, 56, 597-612.

Sales, L. M. \& Silva, T. M. 2012. Staphylococcus aureus meticilna resistente: Um desafio para a saúde pública. Acta Biomedica Brasiliensia, 3, $1-13$.

Silva Junior, A. C. S., Barbosa, F. H. F. \& Monteiro, J. F. 2016. Aspectos higienicosanitários na comercialização no mercado de pescado igarapé das mulheres, Macapá-AP. Biota Amazônia (Biote Amazonie, Biota Amazonia, Amazonian Biota), 6, 15-19.

Silva Júnior, A. C. S., Ferreira, L. R. \& Frazão, A. S. 2017. Avaliação da condição higiênicosanitária na comercialização de pescado da feira do produtor rural do Buritizal, MacapáAmapá. Life Style, 4, 71-81.

Silva Júnior, A. C. S., Silva, A. C. S., Barbosa, F. H. F., Proietti Junior, A. A., Palha, S. E. M. \& Emin, E. T. 2015. Avaliação microbiológica de pescada branca (Cynoscion spp) comercializada na feira do pescado, Macapá AP. Higiene Alimentar, 29, 108-112.

Tavares, W. 2000. Bactérias gram-positivas problemas: resistência do estafilococo, do enterococo e do pneumococo aos antimicrobianos. Revista da Sociedade Brasileira de Medicina Tropical, 33, 281-301.

Valente, D. \& Passos, A. D. C. 2004. Avaliação higiênico-sanitária e físico-estrutural dos supermercados de uma cidade do Sudeste do Brasil. Revista Brasileira de Epidemiologia, 7, 80-87.

\section{Article History:}

Received 7March 2018

Accepted 16 March 2018

Available online 30 April 2018

License information: This is an open-access article distributed under the terms of the Creative Commons Attribution License 4.0, which permits unrestricted use, distribution, and reproduction in any medium, provided the original work is properly cited. 